\title{
Health-related quality of life in children and adolescents with congenital diaphragmatic hernia: a cross-sectional study
}

\author{
Katarina Bojanić ${ }^{\dagger}$, Ruža Grizeljj ${ }^{2 \dagger}$ Jurica Vuković², Lana Omerza², Marina Grubić ${ }^{2}$, Tomislav Ćaleta², \\ Toby N. Weingarten ${ }^{3}$, Darrell R. Schroeder ${ }^{4}$ and Juraj Sprung ${ }^{3^{*}}$ (1)
}

\begin{abstract}
Background: Patients with congenital diaphragmatic hernia $(C D H)$ have a high residual morbidity rate. We compared self-reported health-related quality of life (HRQoL) between patients with CDH and healthy children.

Methods: Forty-five patients with CDH who were born from January 1, 1990, through February 15, 2015, were matched to healthy, age-matched control participants at a 1:2 ratio. The health records of the study participants were reviewed to determine comorbid conditions, and HRQoL was assessed by both the participants and their parents with the Pediatric Quality of Life Inventory (PedsQL). The HRQoL scores of the patients with CDH and the control participants were compared by using analysis of variance to adjust for age group and sex. Among patients with CDH, analysis of variance was used to compare HRQoL scores across groups defined according to their characteristics at initial hospitalization, postdischarge events, and comorbid conditions.

Results: Compared with control participants, patients with CDH had lower mean PedsQL scores, as reported by the parent and child, for the physical and psychosocial domains $(P<0.001)$. Risk factors associated with lower parentreported HRQoL included bronchopulmonary dysplasia, longer initial hospitalization, severe cognitive impairment, and orthopedic symptoms; among patients with CDH, low HRQoL was associated with chronic respiratory issues.

Conclusion: Patients with CDH had lower HRQoL compared with healthy participants. Parent-reported HRQoL tended to be higher than child-reported HRQoL. Results were also inconsistent for the risk factors associated with HRQoL obtained by using child- and parent-reported scores. Therefore, when interpreting HRQOL in CDH survivors, a proxy report should not be considered a substitute for a child's self-report.
\end{abstract}

Keywords: Congenital diaphragmatic hernia, Survivors, Health-related quality of life, Cross-sectional studies

\section{Background}

Assessment of chronically ill children and adolescents with quality of life (QoL) instruments provides subjective information about well-being in various domains of daily life. Better understanding of health-related QoL (HRQoL) of these patients may enable health practitioners to better understand disease-specific symptoms, their association with psychosocial functioning, and the development in the daily life of children $[1,2]$; this may ultimately help clinical

\footnotetext{
* Correspondence: sprung.juraj@mayo.edu

${ }^{\dagger}$ Equal contributors

${ }^{3}$ Division of Multispecialty Anesthesia, Mayo Clinic, 200 First Street SW,

Rochester, MN 55905, USA

Full list of author information is available at the end of the article
}

decision-making and parent counseling [3-5]. Bochdalek congenital diaphragmatic hernia $(\mathrm{CDH})$ is a rare developmental defect of the diaphragm that causes the abdominal viscera to herniate into the chest. Patients with $\mathrm{CDH}$ have high morbidity and mortality rates $[6,7]$. $\mathrm{CDH}$ manifests when the diaphragm fails to close during development, and the abdominal contents migrate into the chest through this defect; pulmonary hypoplasia results because there is limited room for the lungs to grow. These patients often have pulmonary hypertension, asthma, gastrointestinal reflux disease, feeding disorders, developmental delays, and other comorbid conditions that may persist into adulthood [8-15]. This poor health status can substantially affect QoL. Few studies have described HRQoL in patients with 
$\mathrm{CDH}[14,16-19]$. One study reported that 6- to 16-yearold patients with $\mathrm{CDH}$ have lower HRQoL than similarly aged healthy children [14]. Michel et al. [18] reported considerably lower HRQoL scores for patients with $\mathrm{CDH}$ who were 2.6 to 13.8 years old than for age- and sex-matched control participants. In a cross-sectional study that included patients born from 1969 through 1996, Poley et al. [19] found that these differences in HRQoL between patients with $\mathrm{CDH}$ and healthy control patients decreased with age. However, given the cross-sectional nature of that study, the enrolled patients were born when the primary treatment of $\mathrm{CDH}$ was considerably different than current treatment; therefore, differences among age groups could be due to survival bias or changes in treatment modalities. This rare patient population is most commonly examined using cross-sectional studies, and contemporary cohorts consisting of patients with $\mathrm{CDH}$ born after the introduction of new therapeutic modalities (eg, protective ventilation, extracorporeal membrane oxygenation [20-22]) are needed.

Our institution is a tertiary referral center in Croatia for patients with $\mathrm{CDH}$. Our institutional registry of patients with $\mathrm{CDH}$ provides the opportunity to study patients with $\mathrm{CDH}$, and describe temporal effects of $\mathrm{CDH}$ on physical and mental function $[6-9,23,24]$. The primary objective of the current cross-sectional study was to compare HRQoL between patients with $\mathrm{CDH}$ and a control group of similarly aged, healthy children. The Pediatric Quality of Life Inventory (PedsQL) [25], a generic HRQoL questionnaire, is one of the most commonly used instruments for the assessment of physical, mental, and social domains in healthy persons and persons with functional limitations [26, 27]. We hypothesized that PedsQL scores would be significantly lower for CDH survivors compared to healthy controls. The secondary objective was to examine potential associations among $\mathrm{CDH}$ characteristics at initial presentation (eg, severity of presentation at birth), postdischarge events, and HRQoL scores of patients with $\mathrm{CDH}$. QoL is not only a measure of health but also reflects health perceptions and expectations, which may be influenced by physical, psychological, and socioeconomic characteristics. Because PedsQL allows assessment of the child self-report and the parentproxy report, and because of the inherent subjectivity of assessing QoL, our tertiary objective was to evaluate cross-informant variance in HRQoL ratings between parents and their children with $\mathrm{CDH}$. We aimed to determine whether the proxy report could be used as a substitute for the child's self-report for assessing QoL in patients with $\mathrm{CDH}$.

\section{Methods}

This study was approved by the Institutional Ethics Committee of University Hospital Centre in Zagreb, Croatia.
All procedures were conducted in accordance with the ethical standards of the institutional or national research committee, the 1964 Helsinki Declaration and its later amendments, or comparable ethical standards. Written informed consent was obtained from all participants or their legal guardians.

\section{Study design and participants Patients with $\mathrm{CDH}$}

This cross-sectional, single-center study of patients with Bochdalek $\mathrm{CDH}$ was conducted at University Hospital Centre, which is the largest Croatian medical center for neonatal care. All patients with CDH born from January 1 , 1990, through February 1, 2015, were invited to participate, and their parents received a telephone call or letter in which the study objectives were described. HRQoL questionnaires were completed by the patients and their parents from March 1, 2015, through September 30, 2015.

\section{Control participants}

Patients with $\mathrm{CDH}$ were matched with healthy control participants at a 1:2 ratio. Control participants were recruited during well-child visits or visits for acute and minor illnesses. Inclusion criteria were similar age to the patients with $\mathrm{CDH}$ and no known chronic medical illness. This approach to recruit control participants by excluding those with chronic conditions has been utilized before [19]. Our control participants and their parents completed the HRQoL questionnaires during the same time frame as the patients with $\mathrm{CDH}$. Except for sex and age, no demographic information was collected about the control participants.

\section{Data collection and interviews}

In accordance with the original PedsQL administration guidelines, questionnaires were completed by the participants and their parents before the completion of other health data forms or the child's physical examination. Parents or participants independently completed the questionnaires without consultation.

\section{HRQoL evaluation}

We obtained permission to use the PedsQL questionnaire (version 4.0) [25]. This instrument has been validated to evaluate healthy children and adolescents, as well as patients with acute and chronic health conditions $[26,27]$. The PedsQL questionnaire provides a child selfreport (for children $\geq 5$ years) and a parent-proxy report (for children $>2$ years). Therefore, for children younger than 5 years, only their parents completed the ageappropriate HRQoL forms. For infants 1 to 12 and 13 to 24 months old, we obtained parent-proxy reports by using the PedsQL infant scales. Infant Scales, include 36 items for 1 to 12 -month-old infants and 45 items for 
13 to 24-month-old children that assess 5 dimensions (physical, emotional, social, and cognitive functioning and physical symptoms). For 2 to 4-year-old children, we used the PedsQL Parent Report for Toddlers, which includes 21 items that assess 4 dimensions (physical, emotional, social, and preschool functioning). For the children ages 5 to 7,8 to 12 , and 13 to 18 years old, and young adults older than 18 up to 25 years old (PedsQL Young Adult Version) the self-report scales include 23 items, which differ slightly according to age group, that assess 4 dimensions (physical, emotional, social, and school functioning). Parents and older children ( $\geq 5$ years) self-administered PedsQL after receiving instructions. However, for 5 to 7-year-old children, PedsQL was administered by reading the instructions to them (each item was read word-for-word) and providing a separate page that showed 3 facial expressions (ie, pictorial representations) to help the child understand how to answer. Children aged 8 years and older scored questions using a 5 -point Likert scale ( 0 [never] to 4 [almost always]), and 5- to 7-year-old children used a 3-point Likert scale anchored to the pictorial representations.

Although the PedsQL questionnaire introduces various items (ie, questions) for different ages, the forms, regardless of age group, are essentially identical and only differ in the developmentally appropriate language that is used. Each response receives a value of $0 \%, 25 \%, 50 \%$, or $100 \%$ (representing a range from "never" to "always") [25]. The sum of the items divided by the number of answered items generates the mean score. All responses were tabulated to generate an overall health score and physical health summary score. A psychosocial health summary score was calculated using the sum of the answered items in the emotional, social, school, and cognitive (or school) function domains; separate scores were also calculated for each of these subdomains in accordance with published recommendations [25].

\section{Perinatal health information and childhood medical history}

After completion of PedsQL, all patients (or their parents) were interviewed to obtain their medical and surgical histories. This interview was conducted by a neonatologist (K.B.). In addition, participant health records were reviewed to determine their demographic, neonatal, and postnatal characteristics and medical histories. The collected perinatal variables were sex, gestational age, birth weight, postnatal duration of mechanical ventilation, duration of hospitalization, history of bronchopulmonary dysplasia (BPD) (as defined by Jobe and Bancalari) [28], type of $\mathrm{CDH}$ in regard to the liver position ("liver up" vs "liver down," describes whether liver was herniated ["up"] or not ["down"] into the thoracic cavity), and congenital anomalies. By using birth weight and Apgar score at $5 \mathrm{~min}$, we calculated probability of survival scores as proposed by the Congenital Diaphragmatic Hernia Study Group (Apgar score assesses 5 vital signs-appearance, pulse, grimace, activity, respiration-at 1 and 5 min after birth, with the final score ranging from 0-10) [29]. This score assigns the probability of survival after birth, and neonates are categorized as having low $(0 \%-33 \%)$, intermediate $(34 \%-66 \%)$, or high $(67 \%-100 \%)$ survival probability. Of note, this score is the accepted tool for grading $\mathrm{CDH}$ severity after birth. A recurrent respiratory infection (RRI) was defined as at least 3 respiratory episodes per year (or per fall-winter season) for at least 2 years and included treatment for wheezing and breathlessness [30]. Gastroesophageal reflux disease was recorded when indicated in the health records or when the patient received treatment. Furthermore, patients with $\mathrm{CDH}$ and their parents were interviewed to obtain information about current and chronic clinical issues using an inventory that was partly adopted from Michel et al. [18]. We considered 4 major health categories: digestive, respiratory, neuropsychological, and orthopedic. Digestive issues included oral aversion and chronic problems (eg, vomiting, reflux, constipation, diarrhea, abdominal pain, history of gastrointestinal surgery). Chronic respiratory issues included dyspnea at rest, exertional dyspnea, nocturnal dyspnea, chest pain, RRI, use of respiratory medications, and hospitalization for respiratory illness. Neuropsychological issues included cerebral palsy and major cognitive impairment (all patients were formally tested for neurocognitive function, and the results were previously reported [9]). Orthopedic issues included skeletal deformities or any orthopedic treatment. Finally, patients and their parents were asked about all hospital readmissions (following the initial hospitalization for $\mathrm{CDH}$ treatment) and surgical history.

\section{Data management}

Parent- and child-reported HRQoL scores were compared between patients with $\mathrm{CDH}$ and control participants. Analysis of variance was used to adjust for sex and PedsQL questionnaire age group (infants: 1-12 months; infants: 13-24 months; toddlers: 2-4 years; young children: 57 years; children: 8-12 years; teens: 13-18 years; and young adults: $18-25$ years). For these analyses, the ageand sex-adjusted differences between groups (patients with $\mathrm{CDH}$ vs control participants) are calculated using a multivariate regression mode with differences between groups ( $\mathrm{CDH}$ vs control) presented for all scores using model estimates along with the corresponding 95\% CI. Overall HRQoL scores were compared between parents and children using the paired $t$ test when both assessments were available. To assess whether differences between parent-proxy report and child self-report were dependent on the age of the child, a repeated measure analysis of variance was performed with respondent (parent vs child), age 
group, and the respondent-by-age group interaction term included as the explanatory variables. In addition, in analyses restricted to $\mathrm{CDH}$ survivors and their parents, the association of HRQoL scores with $\mathrm{CDH}$ characteristics at initial hospitalization, postdischarge events, and comorbid conditions, was assessed using analysis of variance. Separate analyses were performed for parent proxy reports, and child self-reports. In order to create groups of sufficient size for meaningful comparisons when analyzing age at testing, the two infant groups ( $<12$ months, 13-24 months) were combined, as were children 5 to 7 and 8 to 12 years of age, and those 13 years of age and older. The analysis of child selfreports include only those $\geq 5$ years of age at the time of testing since only parent reports were available for infants and children $<5$ years old. Multiple comparison adjustments were not performed, and in all cases unadjusted 2-tailed $P$ values are reported.

\section{Results}

\section{Study population}

A total of 98 neonates with $\mathrm{CDH}$ were treated at University Hospital Centre from 1990 through 2015, and 44 neonates were known to have died at study recruitment (Fig. 1). Of the remaining 54 patients, 45 agreed to participate, 3 declined, and 6 were lost to follow-up. Therefore, in the current study, we examined self-reported HRQoL in 45 patients with $\mathrm{CDH}$ and 90 control participants. Patients with $\mathrm{CDH}$ had a mean (SD) age of 8.2 (5.7) years, and 29 patients $(64 \%)$ were male. The number of $\mathrm{CDH}$ patients included in each of the PedsQL version- specific age groups is presented in the Fig. 1. The mean (SD) age of the control participants was 8.4 (6.1) years, and 40 participants (44\%) were male.

\section{Comorbid conditions in patients with $\mathrm{CDH}$}

Among patients with $\mathrm{CDH}, 39$ had left-sided $\mathrm{CDH}$ and 6 had right-sided $\mathrm{CDH} ; 12$ patients were prenatally diagnosed. Additional demographic, disease, and immediate postnatal surgical characteristics of these patients are shown in Table 1. The burden of these residual comorbid conditions was substantial (see the patient summary in the Appendix). Thirtythree patients with $\mathrm{CDH}(73 \%)$ were readmitted to the hospital at least 1 time (115 total readmissions) following their initial hospital discharge. The most common reason for subsequent hospitalization was related to respiratory problems (62 readmissions, of which the majority were for RRI), followed by digestive problems (26 readmissions). The remaining 27 readmissions were for a variety of reasons.

At the time of HRQoL testing, 29 patients with $\mathrm{CDH}$ (64\%) reported recent respiratory issues, of which RRI was the most common (25 patients [56\%]). Of these 25 patients with RRI, 9 (36\%) had a history of BPD (6 patients had severe to moderate $\mathrm{BPD}$, and 3 patients had mild $\mathrm{BPD}$ ). Interestingly, 6 patients with BPD did not report a recent RRI (all patients had mild BPD and were $>10$ years).

Twenty-three patients (51\%) had digestive issues. Constipation was the most commonly reported problem (23 patients [51\%]), followed by recurrent diarrhea and gastroesophageal reflux disease (each reported by 5 patients [11\%]). Orthopedic issues affected 6 patients (13\%), including 1 patient with pectus excavatum and restrictive pulmonary disease and 1 patient with kyphoscoliosis that required bracing therapy. Neurologic issues were identified in 7 patients with $\mathrm{CDH}(16 \%)$; all of these patients had severe cognitive impairment (including 1 patient with cerebral palsy).

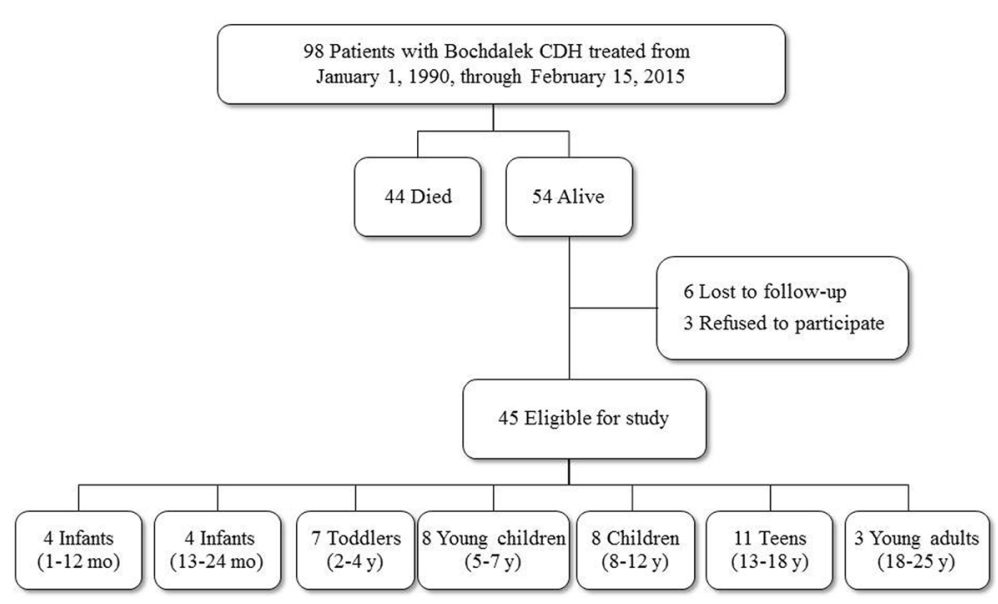

Fig. 1 Exclusion and Enrollment of Patients With Bochdalek Congenital Diaphragmatic Hernia Treated at University Hospital Centre in Zagreb, Croatia. Abbreviations: $\mathrm{CDH}$, congenital diaphragmatic hernia; mo, months; $y$, years 
Table 1 Demographic, Disease, and Surgical Characteristics of Patients With CDH at Birth $(n=45)$

\begin{tabular}{|c|c|}
\hline Characteristic & Value \\
\hline Prenatal diagnosis, n (\%) & $12(26.7)$ \\
\hline Male sex, n (\%) & $29(64.4)$ \\
\hline Gestational age, mean (SD), weeks & $38.7(2)$ \\
\hline Birth weight, mean (SD), kg & $3.11(0.53)$ \\
\hline Apgar score at 5 min, mean (SD) & $7.8(2.2)$ \\
\hline \multicolumn{2}{|l|}{ Probability of survival, $\mathrm{n}(\%)$} \\
\hline High (67\%-100\%) & $31(68.9)$ \\
\hline Intermediate (34\%-66\%) & $12(26.7)$ \\
\hline Low $(0 \%-33 \%)$ & $2(4.4)$ \\
\hline \multicolumn{2}{|l|}{$\mathrm{CDH}$ side, $\mathrm{n}(\%)^{\mathrm{a}}$} \\
\hline Left & $39(86.7)$ \\
\hline Right & $6(13.3)$ \\
\hline Duration of hospitalization, median (IQR), days & $28(18-57)$ \\
\hline Congenital anomalies, n (\%) & $25(55.6)$ \\
\hline Cardiovascular $^{\mathrm{b}}$ & $7(15.6)$ \\
\hline Renal $^{c}$ & $4(8.9)$ \\
\hline Gastrointestinal $^{d}$ & $4(8.9)$ \\
\hline Skeletal ${ }^{e}$ & $7(15.6)$ \\
\hline Other $^{f}$ & $3(6.7)$ \\
\hline
\end{tabular}

$C D H$ Congenital diaphragmatic hernia, IQR Interquartile range, $S D$ Standard deviation

a Seven patients with left-sided CDH were "liver up"; all 6 patients with rightsided CDH were "liver up"

${ }^{\mathrm{b}}$ Includes patent foramen ovale $(n=1)$, atrial septal defect II $(n=3)$, and

patent ductus arteriosus $(n=3)$

'Includes hydronephrosis $(n=2)$, multicystic kidney $(n=1)$, and hypoplastic kidney $(n=1)$

${ }^{d}$ Includes accessory spleen $(n=2)$ and Meckel diverticulum $(n=2)$

e Includes foot deformities $(n=3)$ and abnormal number of ribs $(n=4)$

f Includes macroglossia $(n=1)$, neck fistula $(n=1)$, and preauricular tag $(n=1)$

\section{PedsQL scores of patients with CDH and control} participants

Table 2 shows the parent- and child-reported HRQoL scores of the patients with $\mathrm{CDH}$ and control participants. Patients with $\mathrm{CDH}$ had significantly lower HRQoL (as reported by the parent-proxy report and patient self-report) compared with control participants, as shown by the overall scores, physical health summary scores, and psychosocial health summary scores (all $P<0.001$ ) and the scores on the emotional, social, and school subdomains (all $P \leq$ 0.02). The only nonsignificant finding between control participants and patients with $\mathrm{CDH}$ was the parentreported cognitive scores for 1- to 24-month-old children $(P=0.69)$. In the analysis restricted to complete child and parent pairs (ie, both completed HRQoL assessments [ 28 patients with $\mathrm{CDH}$ and 60 control participants]), the child's self-reported scores were significantly lower than the parent-reported scores. The mean (SD) overall scores were 75.0 (13.9) for patients with $\mathrm{CDH}$ and 80.6 (12.0) for their parents $(P=0.046)$. The difference between parent and child reports was not found to be dependent on the child's at testing (respondent-by-age interaction $P=0.769$ ). The mean (SD) overall scores were 85.4 (8.8) for control participants and $88.8(6.8)$ for their parents $(P<0.001)$, with no evidence of an interaction between respondent and age at testing (respondent-by-age interaction $P=0.533$ ).

Tables 3 and 4 present the HRQoL scores of the patients with $\mathrm{CDH}$ according to their characteristics at birth (including $\mathrm{CDH}$ severity) and after their initial hospital discharge. Among patients with $\mathrm{CDH}$, these exploratory analyses showed that parent-reported HRQoL was lower when their children also had BPD, longer initial hospitalization, severe neurologic issues (most commonly severe cognitive impairment), or orthopedic symptoms; in addition, parent-reported HRQoL differed by the child's age, and 5- to 12-year-old patients had the lowest HRQoL (Table 3). Among patients with $\mathrm{CDH}$, a recent history of pulmonary symptoms was the only characteristic that was negatively associated with HRQoL (Table 4).

\section{Discussion}

Many of our patients with CDH had substantial comorbid conditions (Appendix), and these comorbid conditions may have affected HRQoL. Using PedsQL, we found that the HRQoL of the patients with $\mathrm{CDH}$, as measured by the child self-reports and parent-proxy reports, was considerably lower than that of the control participants. For both parent-proxy reports and child self-reports, the magnitude of QoL reduction was consistent for the overall score and all relevant subscores. The child self-reports showed significantly lower QoL than the parent-proxy reports; therefore, when interpreting QoL in CDH survivors, a proxy report should not be considered a substitute for a child's self-report. This finding should be considered in situations when only proxy HRQoL report is available for decision-making [31]. In addition, discordance was found between patients with $\mathrm{CDH}$ and their parents in regard to specific characteristics associated with low HRQoL. For example, respiratory disease was the only characteristic markedly associated with low HRQoL in the child self-reports, but several characteristics-all descriptors of postnatal $\mathrm{CDH}$ severity-were associated with lower HRQoL when reported in the parent-proxy reports.

\section{Parent-proxy and child self-reports of HRQoL and charac- teristics associated with HRQoL}

Because of the lower cognitive and language skills of young children, PedsQL includes parent-proxy reports to obtain information about children. The use of questionnaires with child and parent versions has raised questions about the level of agreement between children and their parents about child functioning. Some investigators reported poor parent-child agreement [32, 33], but others reported 
Table 2 Parent- and Child-Reported PedsQL Scores of Patients With CDH and Control Participants ${ }^{\mathrm{a}}$

\begin{tabular}{|c|c|c|c|c|c|c|c|}
\hline \multirow[b]{2}{*}{ Assessment } & \multicolumn{2}{|c|}{ Participants With CDH } & \multicolumn{2}{|c|}{ Healthy Control Participants } & \multicolumn{3}{|c|}{ Estimated Difference $(\mathrm{CDH}-\text { Control) })^{\mathrm{b}}$} \\
\hline & $\bar{n}$ & Mean Score (SD) & $\mathrm{n}$ & Mean Score (SD) & Estimate & $95 \% \mathrm{Cl}$ & $P$ Value \\
\hline \multicolumn{8}{|l|}{ Parent report } \\
\hline Overall score & 45 & $81.2(14.8)$ & 90 & $89.2(6.4)$ & -8.2 & -11.7 to -4.7 & $<0.001$ \\
\hline Physical health summary & 45 & $82.2(17.0)$ & 90 & $90.5(8.4)$ & -8.3 & -12.5 to -4.1 & $<0.001$ \\
\hline Psychosocial health summary & 45 & $80.1(15.4)$ & 90 & $88.5(6.9)$ & -8.5 & -12.2 to -4.7 & $<0.001$ \\
\hline Emotional & 45 & $75.8(15.2)$ & 90 & $83.1(11.0)$ & -8.0 & -12.5 to -3.5 & $<0.001$ \\
\hline Social & 45 & $85.6(19.5)$ & 90 & $93.2(8.8)$ & -7.3 & -11.9 to -2.8 & 0.002 \\
\hline School & 37 & $79.3(21.2)$ & 74 & $91.0(9.3)$ & -11.5 & -17.2 to -5.8 & $<0.001$ \\
\hline Cognitive $^{c}$ & 8 & $90.6(11.1)$ & 16 & $92.8(9.9)$ & -1.8 & -10.8 to 7.2 & 0.69 \\
\hline \multicolumn{8}{|l|}{ Child report } \\
\hline Overall score & 28 & $75.0(13.9)$ & 60 & $85.4(8.8)$ & -10.7 & -15.6 to -5.9 & $<0.001$ \\
\hline Physical health summary & 28 & $74.7(16.5)$ & 60 & $84.8(11.6)$ & -10.7 & -16.7 to -4.7 & $<0.001$ \\
\hline Psychosocial health summary & 28 & $75.4(14.6)$ & 60 & $85.6(8.9)$ & -10.3 & -15.4 to -5.3 & $<0.001$ \\
\hline Emotional & 28 & $69.6(16.6)$ & 60 & $79.8(13.5)$ & -10.8 & -17.4 to -4.2 & 0.002 \\
\hline Social & 28 & $82.7(18.3)$ & 60 & $89.9(9.9)$ & -6.9 & -12.9 to -1.0 & 0.02 \\
\hline School & 28 & $73.2(19.6)$ & 60 & $86.8(10.9)$ & -13.9 & -20.4 to -7.4 & $<0.001$ \\
\hline
\end{tabular}

CDH Congenital diaphragmatic hernia, PedsQL Pediatric Quality of Life Inventory, SD Standard deviation

${ }^{a}$ Patients with $\mathrm{CDH}$ had a mean (SD) age of 8.2 (5.7) years and consisted of 29 males (64\%) and 16 females (36\%). Control participants had a mean (SD) age of 8.4 (6.1) years and consisted of 40 males (44\%) and 50 females (56\%)

$\mathrm{b}$ The difference between patients with $\mathrm{CDH}$ and control was estimated using multiple regression with group (CDH vs. control) as the explanatory variable of interest and age group and sex included as adjustor variables

'Only reported by the parents of 1 - to 24 -month-old infants. For this age group, the psychosocial health summary score is calculated as the sum of the items divided by the number of items answered in the emotional, social, and cognitive functioning scales

moderate to high agreement $[34,35]$. One study used both child self-reports and parent-proxy reports to evaluate QoL of patients with $\mathrm{CDH}$ [18], but to our knowledge our study is the first to simultaneously obtain child self-reports and parent-proxy reports by using a validated instrument and to directly compare these sources. In our study, parentreported HRQoL was slightly but consistently higher than child-reported HRQoL. When patient and disease characteristics were tested for potential associations with HRQoL, our findings were inconsistent between parent and child assessments. The lack of agreement among individual variables associated with child- and parent-reported HRQoL scores may be due to complex, interrelated, overlapping disease characteristics; thus, identifying a single characteristic that is consistently associated with low HRQoL is difficult. Patients with $\mathrm{CDH}$ may have complex comorbid conditions that contribute to low HRQoL scores in diverse ways when reported by a child versus a parent. In our study, the characteristics that are descriptors of the severity of the postnatal course were not associated with reduced HRQoL scores in the child self-reports. Similarly, Koivusalo et al. [17] observed lower than expected HRQoL in 25\% of patients with $\mathrm{CDH}$, but no correlation between $\mathrm{CDH}$ severity and HRQoL scores was reported. A single variable-chronic respiratory problems, which are often linked with multiple hospitalizations-was associated with low child self-reported HRQoL in our study. In contrast, longer initial hospitalization, postnatal BPD, severe cognitive impairment, and chronic orthopedic problems were all associated with lower HRQoL when reported by parents but not children.

Discordant perceptions of HRQoL between child selfreports and parent-proxy reports have been reported $[36,37]$. In many instances, when the parent and child disagree, the evidence does not clearly show that parents overestimated or underestimated HRQoL. Glaser et al. [35] suggested that parents can appropriately report information about their child's HRQoL, but others indicated that parents tend to rate their child's HRQoL lower than their child [32, 33]. Davis et al. [31] suggested that "discordance in HRQoL scores between parents and children may be due to different reasoning and response styles rather than item interpretation." In a study by Saigal et al. [38], parents were asked to rate the HRQoL of their infants with extremely low birth weight, and, despite the presence of substantial disease burden, average HRQoL was high. In our study, the scores of the parent-proxy reports were consistently higher than the scores of the child self-reports. Investigations of adult populations have shown that patients are more reliable and consistent at scoring their own QoL than their physicians [39, 40]; therefore, patient reports should be the criterion standard when this information is used for interventions and treatments. Another study assessed 
Table 3 Parent-Reported Quality of Life Scores of Patients With CDH Stratified by Characteristics at Birth, CDH Severity, and Major Lifetime Comorbid Conditions

\begin{tabular}{|c|c|c|c|c|c|c|c|}
\hline Characteristic & Patients (n) & $\begin{array}{l}\text { Mean Overall } \\
\text { Score (SD) }\end{array}$ & $P$ Value* & $\begin{array}{l}\text { Mean Physical } \\
\text { Score (SD) }\end{array}$ & $P$ Value* & $\begin{array}{l}\text { Mean Psychosocial } \\
\text { Score (SD) }\end{array}$ & $P$ Value $^{*}$ \\
\hline \multicolumn{8}{|l|}{ Characteristics at birth } \\
\hline Sex & & & 0.38 & & 0.72 & & 0.35 \\
\hline Male & 29 & $82.7(15.4)$ & & $82.9(18.3)$ & & $81.7(16.0)$ & \\
\hline Female & 16 & $78.5(13.5)$ & & $81.0(14.9)$ & & $77.1(14.5)$ & \\
\hline Probability of survival score & & & 0.08 & & 0.06 & & 0.08 \\
\hline Low or intermediate & 14 & $75.5(18.1)$ & & $75.0(20.1)$ & & $74.0(18.4)$ & \\
\hline High & 31 & $83.7(12.5)$ & & $85.4(14.7)$ & & $82.8(13.3)$ & \\
\hline CDH type & & & 0.81 & & 0.94 & & 0.62 \\
\hline Liver down & 32 & $80.8(13.4)$ & & $82.1(15.7)$ & & $79.3(14.3)$ & \\
\hline Liver up & 13 & $82.1(18.3)$ & & $82.5(20.7)$ & & $81.9(18.5)$ & \\
\hline $\mathrm{BPD}$ & & & 0.003 & & 0.01 & & 0.007 \\
\hline Yes & 15 & $72.2(19.2)$ & & $73.3(20.3)$ & & $71.5(20.0)$ & \\
\hline No & 30 & $85.7(9.5)$ & & $86.7(13.4)$ & & $84.4(10.5)$ & \\
\hline Initial hospitalization, days & & & 0.01 & & 0.15 & & 0.008 \\
\hline$\leq 30$ & 24 & $86.9(8.3)$ & & $86.1(14.1)$ & & $86.4(8.6)$ & \\
\hline $31-60$ & 11 & $77.4(10.3)$ & & $81.4(16.3)$ & & $75.0(10.1)$ & \\
\hline$\geq 61$ & 10 & $71.3(23.7)$ & & $73.7(22.3)$ & & $70.4(24.9)$ & \\
\hline Mechanical ventilation, days & & & 0.08 & & 0.07 & & 0.12 \\
\hline$\leq 7$ & 22 & $86.6(8.8)$ & & $88.5(12.3)$ & & $85.4(9.4)$ & \\
\hline $8-21$ & 13 & $78.4(13.0)$ & & 78.7 (15.6) & & $76.8(14.1)$ & \\
\hline$\geq 22$ & 9 & $76.6(20.0)$ & & $75.2(23.3)$ & & $77.1(19.6)$ & \\
\hline \multicolumn{8}{|l|}{ Postdischarge events } \\
\hline Hospitalizations, n & & & 0.08 & & 0.03 & & 0.13 \\
\hline 0 & 12 & $86.8(10.0)$ & & $88.3(9.5)$ & & $85.8(12.1)$ & \\
\hline $1-2$ & 17 & $83.1(10.2)$ & & $86.3(15.1)$ & & $81.5(10.0)$ & \\
\hline$\geq 3$ & 16 & 74.9 (19.6) & & $73.3(20.2)$ & & $74.3(20.5)$ & \\
\hline \multicolumn{8}{|l|}{ Characteristics at testing } \\
\hline Age & & & 0.03 & & 0.045 & & 0.03 \\
\hline$<24$ months & 8 & $83.8(9.2)$ & & $83.9(7.8)$ & & $83.7(11.3)$ & \\
\hline $2-4$ years & 7 & $93.2(5.8)$ & & $97.3(4.9)$ & & $90.7(7.3)$ & \\
\hline $5-12$ years & 18 & $74.5(17.2)$ & & 76.4 (19.0) & & $72.5(18.2)$ & \\
\hline$\geq 13$ years & 12 & $82.4(13.1)$ & & $81.0(18.5)$ & & $82.8(12.2)$ & \\
\hline Digestive issues & & & 0.06 & & 0.046 & & 0.07 \\
\hline Yes & 23 & $77.2(17.2)$ & & 77.3 (19.3) & & 76.0 (17.9) & \\
\hline No & 22 & $85.4(10.5)$ & & $87.3(12.7)$ & & $84.3(11.3)$ & \\
\hline Respiratory issues & & & 0.40 & & 0.13 & & 0.62 \\
\hline Yes & 29 & $79.8(15.7)$ & & 79.3 (17.8) & & 79.2 (16.3) & \\
\hline No & 16 & 83.7 (13.0) & & $87.4(14.7)$ & & $81.6(14.1)$ & \\
\hline Orthopedic issues & & & 0.01 & & 0.007 & & 0.04 \\
\hline Yes & 6 & $67.0(21.9)$ & & $65.1(23.4)$ & & $68.1(22.1)$ & \\
\hline No & 39 & $83.4(12.3)$ & & $84.8(14.5)$ & & 81.9 (13.6) & \\
\hline
\end{tabular}


Table 3 Parent-Reported Quality of Life Scores of Patients With CDH Stratified by Characteristics at Birth, CDH Severity, and Major Lifetime Comorbid Conditions (Continued)

\begin{tabular}{|c|c|c|c|c|c|c|c|}
\hline Characteristic & Patients (n) & $\begin{array}{l}\text { Mean Overall } \\
\text { Score (SD) }\end{array}$ & P Value* & $\begin{array}{l}\text { Mean Physical } \\
\text { Score (SD) }\end{array}$ & P Value* & $\begin{array}{l}\text { Mean Psychosocial } \\
\text { Score (SD) }\end{array}$ & $P$ Value* \\
\hline Neurologic issues & & & $<0.001$ & & 0.05 & & $<0.001$ \\
\hline$Y_{e s}^{a}$ & 7 & $64.7(22.6)$ & & $70.8(24.3)$ & & $60.4(21.1)$ & \\
\hline No & 38 & $84.2(10.7)$ & & $84.3(14.8)$ & & $83.7(11.1)$ & \\
\hline
\end{tabular}

BPD Bronchopulmonary dysplasia, $C D H$ Congenital diaphragmatic hernia, SD Standard deviation. All scores are expressed as mean (SD)

${ }^{a}$ All 7 patients with $\mathrm{CDH}$ and neurologic issues had severe cognitive impairment; 1 patient also had cerebral palsy

*The given health-related quality of life score was compared across groups using analysis of variance (ANOVA)

QoL in children with chronic pain and suggested that, although merit should be given to parent-proxy reports, the child's own perspective should be directly solicited whenever possible [2].

\section{Association between age of patients with $\mathrm{CDH}$ and HRQoL scores}

Because numerous comorbid conditions associated with $\mathrm{CDH}$ in early childhood resolve with age and chronic health conditions may affect a person's subjective perception of HRQoL, self-reported HRQoL scores may be affected by the child's age [19, 41]. Poley et al. [19] conducted a cross-sectional study and observed poor HRQoL in young patients with CDH but normal HRQoL in children older than 16 years. Poley et al. concluded that, despite considerable early morbidity, the ultimate prognosis of $\mathrm{CDH}$ as measured with HRQoL is favorable. In contrast, using PedsQL questionnaires, Sheikh et al. [41] reported good HRQoL scores in patients with $\mathrm{CDH}$, even in younger patients (mean age, 5.5 years), regardless of $\mathrm{CDH}$ severity at birth. This discordance between studies may be due to the associations between $\mathrm{CDH}$ and various comorbid conditions (eg, cardiac, pulmonary), which have variable degrees of severity and potential to improve over time. In addition, given the cross-sectional nature of these studies, the association between QoL and age is difficult to interpret, because at the time they were surveyed for the present study, older patients had received treatments when contemporary therapeutic modalities were unavailable, resulting in survival of healthier children; therefore, these older CHD participants may have less-severe residual disease. For all of these reasons, comparison of outcomes in cross-sectional studies is associated with complexities related to unaccounted confounders.

In our study, HRQoL of the patients with $\mathrm{CDH}$ differed with the age of the child. Five- to 12-year-old children had considerably lower parent-reported HRQoL. A plausible, albeit speculative, explanation for this finding is that these children are more engaged in competitive school activities, and therefore parents may notice that their child does not perform at the same level as their peers. Whether this rationale would also apply to child self-reports cannot be assessed because children under the age of 5 years did not complete a questionnaire. However, it appears that a similar perception of low health status exists for 5- to 12-yearold children and their parents because both groups reported low scores (Tables 3 and 4).

\section{Limitations}

This study is limited by its retrospective design. Evaluation of a wide range of ages with a cross-sectional study precludes the ability to precisely assess whether HRQoL changes with time. Given the rarity of $\mathrm{CDH}$, the statistical power to assess differences across age groups is limited by the small number of patients in some age groups. In addition, a parent's assessment of their child's HRQoL may be influenced by unaccounted elements (eg, life experience, expectations for their child, physical and psychological health, socioeconomic status, sex, race and ethnicity, family relationships, and parental stress related to their child's disease) [1, 2]. Furthermore, adaptation to disease may affect a child's perception of HRQoL, but we cannot account for this possibility. In order to ensure that our control group was not skewed by individuals with chronic comorbidities, when selecting control participants, we excluded participants with chronic medical illness. This approach may have overestimated the HRQoL of our control participants compared with the general population.

\section{Conclusions}

Across a wide range of ages, patients with $\mathrm{CDH}$ had lower self-reported HRQoL scores in the physical and psychosocial domains compared with similarly aged, healthy control participants. However, no patient characteristics, comorbid conditions, or symptoms were consistently associated with worse HRQoL in the child or parent assessments. Although we were unable to determine why children reported lower QoL scores, we believe that clinical interventions based on QoL information should primarily consider the child's report, and that the child's own perspective of well-being should be a criterion standard for implementation of corrective measures. Proxy responses for evaluation of QoL in $\mathrm{CDH}$ survivors should be used only when patient responses are not available. 
Table 4 Child-Reported Quality of Life Scores of Patients With CDH Stratified by Characteristics at Birth, CDH Severity, and Major Lifetime Comorbid Conditions

\begin{tabular}{|c|c|c|c|c|c|c|c|}
\hline Characteristic & Patients (n) & $\begin{array}{l}\text { Mean Overall } \\
\text { Score (SD) }\end{array}$ & $P$ Value* & $\begin{array}{l}\text { Mean Physical } \\
\text { Score (SD) }\end{array}$ & $P$ Value* & $\begin{array}{l}\text { Mean Psychosocial } \\
\text { Score (SD) }\end{array}$ & $P$ Value $^{*}$ \\
\hline \multicolumn{8}{|l|}{ Characteristics at birth } \\
\hline Sex & & & 0.56 & & 0.16 & & 0.95 \\
\hline Male & 15 & $76.4(14.3)$ & & $78.8(17.4)$ & & $75.2(14.2)$ & \\
\hline Female & 13 & $73.3(13.7)$ & & $70.0(14.5)$ & & $75.6(15.6)$ & \\
\hline Probability of survival score & & & 0.71 & & 0.89 & & 0.63 \\
\hline Low or intermediate & 8 & $73.4(14.7)$ & & $75.4(14.1)$ & & $73.2(16.8)$ & \\
\hline High & 20 & $75.6(13.9)$ & & $74.4(17.6)$ & & $76.3(13.9)$ & \\
\hline CDH type & & & 0.81 & & 0.42 & & 0.93 \\
\hline Liver down & 22 & $75.3(13.6)$ & & $76.0(15.8)$ & & $75.3(14.2)$ & \\
\hline Liver up & 6 & $73.7(16.2)$ & & $69.8(19.4)$ & & $75.8(17.3)$ & \\
\hline BPD & & & 0.56 & & 0.76 & & 0.47 \\
\hline Yes & 9 & $72.7(12.0)$ & & $73.3(15.6)$ & & $72.4(11.9)$ & \\
\hline No & 19 & $76.0(14.9)$ & & $75.3(17.2)$ & & $76.8(15.8)$ & \\
\hline Initial hospitalization, days & & & 0.48 & & 0.47 & & 0.40 \\
\hline$\leq 30$ & 15 & $76.3(13.0)$ & & $73.8(15.7)$ & & $78.1(14.0)$ & \\
\hline $31-60$ & 10 & $75.9(15.7)$ & & $78.8(18.3)$ & & $74.3(15.1)$ & \\
\hline$\geq 61$ & 3 & $65.6(12.2)$ & & $65.6(14.3)$ & & $65.6(16.2)$ & \\
\hline Mechanical ventilation, days & & & 0.99 & & 0.93 & & 0.88 \\
\hline$\leq 7$ & 13 & $75.3(16.1)$ & & $73.3(15.7)$ & & $76.9(17.8)$ & \\
\hline $8-21$ & 10 & $74.3(13.3)$ & & $75.6(19.0)$ & & $73.7(12.1)$ & \\
\hline$\geq 22$ & 5 & $75.4(11.2)$ & & $76.3(16.3)$ & & $75.0(11.7)$ & \\
\hline \multicolumn{8}{|l|}{ Postdischarge events } \\
\hline Hospitalizations, n & & & 0.75 & & 0.24 & & 0.39 \\
\hline 0 & 6 & $78.3(8.5)$ & & $70.3(14.4)$ & & $82.7(9.8)$ & \\
\hline $1-2$ & 11 & $75.3(18.1)$ & & $81.3(17.3)$ & & $72.7(18.4)$ & \\
\hline$\geq 3$ & 11 & $72.8(12.0)$ & & $70.5(15.8)$ & & $74.1(11.9)$ & \\
\hline \multicolumn{8}{|l|}{ Characteristics at testing } \\
\hline Age, years & & & 0.76 & & 0.38 & & 0.99 \\
\hline $5-12$ & 16 & $74.3(13.8)$ & & $72.3(16.6)$ & & $75.4(14.4)$ & \\
\hline$\geq 13$ & 12 & $75.9(14.6)$ & & $77.9(16.5)$ & & $75.4(15.4)$ & \\
\hline Digestive issues & & & 0.22 & & 0.51 & & 0.18 \\
\hline Yes & 17 & $72.3(15.5)$ & & $73.0(16.9)$ & & $72.4(16.3)$ & \\
\hline No & 11 & $79.1(10.2)$ & & $77.3(16.2)$ & & $80.0(10.4)$ & \\
\hline Respiratory issues & & & 0.02 & & 0.01 & & 0.10 \\
\hline Yes & 16 & $69.9(14.7)$ & & $68.0(16.4)$ & & $71.4(16.2)$ & \\
\hline No & 12 & $81.7(9.1)$ & & $83.6(11.9)$ & & $80.7(10.3)$ & \\
\hline Orthopedic issues & & & 0.76 & & 0.97 & & 0.67 \\
\hline Yes & 5 & $76.7(10.5)$ & & 74.4 (17.9) & & $78.0(8.0)$ & \\
\hline No & 23 & $74.6(14.7)$ & & $74.7(16.6)$ & & $74.8(15.7)$ & \\
\hline Neurologic issues & & & 0.13 & & 0.27 & & 0.11 \\
\hline Yes & 3 & $63.4(15.8)$ & & $64.6(15.7)$ & & $62.8(20.0)$ & \\
\hline No & 25 & 76.4 (13.3) & & 75.9 (16.4) & & $76.9(13.5)$ & \\
\hline
\end{tabular}




\section{Appendix}

Table 5 Chronic Health-Related Conditions in Patients with $\mathrm{CDH}$

\begin{tabular}{|c|c|c|c|c|c|}
\hline \multirow[t]{2}{*}{ Patient } & \multicolumn{2}{|l|}{ QoL Score } & \multirow[t]{2}{*}{ Age, Sex } & \multirow{2}{*}{$\begin{array}{l}\text { Hospital } \\
\text { Readmissions }{ }^{a} \\
(\mathrm{~N})\end{array}$} & \multirow[t]{2}{*}{ Major Health Issues or Conditions ${ }^{\mathrm{b}, \mathrm{c}}$} \\
\hline & Child Report & $\overline{\text { Parent Report }}$ & & & \\
\hline 1 & NA & 90.3 & $6 \mathrm{mo}, \mathrm{M}$ & 1 & RRI \\
\hline 2 & NA & 78.6 & $7 \mathrm{mo}, \mathrm{M}$ & 1 & DOR, DOE, RRI \\
\hline 3 & NA & 91.4 & $10 \mathrm{mo}, \mathrm{M}$ & 0 & Surgery (clubfoot), RRI \\
\hline 4 & NA & 95.0 & $3 \mathrm{mo}, \mathrm{M}$ & 0 & None \\
\hline 5 & NA & 80.6 & $20 \mathrm{mo}, \mathrm{M}$ & 1 & $\begin{array}{l}\text { Oral aversion, malnourished, } \\
\text { DOE, RRI, inguinal hernia repair }\end{array}$ \\
\hline 6 & NA & 86.0 & $22 \mathrm{mo}, \mathrm{M}$ & 2 & RRI, DOE \\
\hline 7 & NA & 82.2 & $23 \mathrm{mo}, \mathrm{M}$ & 6 & $\begin{array}{l}\text { RRI, atopic dermatitis, inguinal } \\
\text { hernia repair, orchidopexy }\end{array}$ \\
\hline 8 & NA & 66.3 & $16 \mathrm{mo}, \mathrm{F}$ & 0 & Multicystic kidney, IQ $<70$ \\
\hline 9 & NA & 82.1 & $4 y, F$ & 7 & $\begin{array}{l}\text { Galactosemia, cataract } \\
\text { surgery, RRI, IQ }<70\end{array}$ \\
\hline 10 & NA & 95.2 & $3 y, M$ & 1 & Surgery (SBO, $\mathrm{CDH}$ reherniation) \\
\hline 11 & NA & 94 & $3 y, M$ & 0 & None \\
\hline 12 & NA & 100 & $4 y, M$ & 5 & DOE, DOR, nocturnal dyspnea, RRI \\
\hline 13 & NA & 96.4 & $4 y, F$ & 0 & RRI \\
\hline 14 & NA & 95.2 & $4 y, M$ & 0 & RRI \\
\hline 15 & NA & 89.3 & $4 y, M$ & 2 & RRI \\
\hline 16 & NA & 39.1 & $5 y, M$ & 4 & $\begin{array}{l}\text { IQ }<70 \text {, hyperactivity disorder, } \\
\text { DOE, RRI, NPF-up }\end{array}$ \\
\hline 17 & 63.0 & 89.1 & $5 y, F$ & 0 & RRI \\
\hline 18 & 73.9 & 84.9 & $5 y, F$ & 1 & RRI \\
\hline 19 & 81.8 & 85.9 & $5 y, F$ & 0 & RRI, DOE \\
\hline 20 & 78.3 & 82.6 & $5 y, F$ & 0 & None \\
\hline 21 & 45.7 & 83.7 & $5 y, M$ & 2 & RRI, asthma, IQ $<70$ \\
\hline 22 & NA & 35.8 & $7 y, M$ & 4 & $\begin{array}{l}\mathrm{IQ}<70 \text {, cerebral palsy, } \mathrm{DOE}, \mathrm{RRI} \\
\text { NPF-up, difficulty walking, } \\
\text { surgeries (CDH reherniation, } \mathrm{SBO})\end{array}$ \\
\hline 23 & 76.1 & 53.3 & $7 y, F$ & 15 & $\begin{array}{l}\text { Severe pectus excavatum, RRI, } \\
\text { DOE, DOR, oral aversion, GERD, } \\
\text { IQ }<70 \text {, NPF-up, pain ambulating, } \\
\text { surgery (SBO) }\end{array}$ \\
\hline 24 & 62.0 & 72.8 & $8 y, F$ & 4 & $\begin{array}{l}\text { DOE, RRI, hydronephrosis, surgeries } \\
\text { (CDH reherniation, neck fistula, } \\
\text { preauricular tag) }\end{array}$ \\
\hline 25 & 85.9 & 84.8 & $8 y, M$ & 6 & $\begin{array}{l}\text { DOE, RRI, surgery } \\
\text { (equinovarus, orchidopexy) }\end{array}$ \\
\hline 26 & 94.6 & 81.5 & $9 y, M$ & 13 & $\begin{array}{l}\text { NPF-up, oral aversion, malnourished, } \\
\text { GERD, DOE, RRI, surgeries } \\
\text { (adenoidectomy, abdominal } \\
\text { patch removal) }\end{array}$ \\
\hline 27 & 81.5 & 82.6 & $10 y, F$ & 1 & Surgery (SBO) \\
\hline 28 & 52.2 & 54.8 & $11 \mathrm{y}, \mathrm{F}$ & 4 & $\begin{array}{l}\text { NPF-up, seizures, GERD, DOE, } \\
\text { hearing and visual impairment, } \\
\text { surgery (SBO) }\end{array}$ \\
\hline 29 & 75.0 & 89.1 & $11 \mathrm{y}, \mathrm{M}$ & 3 & $\begin{array}{l}\text { Oral aversion, pain ambulating, } \\
\text { selective mutism, NPF-up }\end{array}$ \\
\hline
\end{tabular}


Table 5 Chronic Health-Related Conditions in Patients with CDH (Continued)

\begin{tabular}{|c|c|c|c|c|c|}
\hline \multirow[t]{2}{*}{ Patient } & \multicolumn{2}{|l|}{ QoL Score } & \multirow[t]{2}{*}{ Age, Sex } & \multirow{2}{*}{$\begin{array}{l}\text { Hospital } \\
\text { Readmissions }{ }^{a} \\
(\mathrm{~N})\end{array}$} & \multirow[t]{2}{*}{ Major Health Issues or Conditions ${ }^{b, c}$} \\
\hline & Child Report & $\overline{\text { Parent Report }}$ & & & \\
\hline 30 & 66.3 & 67.3 & 12 y, M & 1 & Adenoidectomy \\
\hline 31 & 89.1 & 86.9 & $12 y, F$ & 0 & $\begin{array}{l}\text { Congenital blindness, attending } \\
\text { special school, NPF-up }\end{array}$ \\
\hline 32 & 71.7 & 80.0 & $12 y, M$ & 5 & $\begin{array}{l}\text { DOE, RRI, surgeries (inguinal hernia } \\
\text { repair, orchidopexy) }\end{array}$ \\
\hline 33 & 91.3 & 88.0 & 13 y, M & 2 & RRI, orchidopexy \\
\hline 34 & 68.5 & 92.4 & 13 y, M & 5 & $\begin{array}{l}\text { NPF-up, IQ }<70 \text {, learning difficulties, } \\
\text { vomiting, RRI, surgeries } \\
\text { (SBO, closure ductus Botalli) }\end{array}$ \\
\hline 35 & 95.7 & 98.9 & 13 y, M & 2 & Surgeries (orchidopexy, hydrocele repair) \\
\hline 36 & 79.4 & 58.69 & $14 y, F$ & 1 & Brace therapy (scoliosis), pain ambulating \\
\hline 37 & 79.4 & 58.7 & 14 y, M & 0 & Primary night enuresis, NPF-up \\
\hline 38 & 83.7 & 100 & 14 y, M & 3 & Atopic asthma \\
\hline 39 & 45.7 & 78.3 & $15 y, F$ & 2 & DOE, adenoidectomy \\
\hline 40 & 64.1 & 70.7 & $15 y, M$ & 1 & GERD, chest pain \\
\hline 41 & 67.4 & 73.9 & 15 y, M & 3 & $\begin{array}{l}\text { CVI due to AV malformation, residual } \\
\text { hemiparesis, loss of visual field, NPF-up }\end{array}$ \\
\hline 42 & 64.1 & 77.2 & $17 y, M$ & 4 & Bronchiectasis, GERD, DOE, RRI \\
\hline 43 & 91.3 & 92.4 & $18 \mathrm{y}, \mathrm{F}$ & 1 & Pain ambulating \\
\hline 44 & 93.5 & 88.0 & $20 y, M$ & 2 & None \\
\hline 45 & 78.3 & 90.2 & $20 y, F$ & 0 & Hashimoto thyroiditis, DOE \\
\hline
\end{tabular}

AV Arteriovenous, $C D H$ Congenital diaphragmatic hernia, $C V I$ Cerebrovascular insult, DOE Dyspnea on exertion, DOR Dyspnea on rest, $F$ Female, GERD Gastroesophageal reflux disease, IQ Intelligence quotient, $M$ Male, N Number, NA Not applicable, NPF-up Neurologic and/or psychiatric follow-up, QoL Quality of life, $R R I$ Recurrent respiratory infection, $S B O$ Small-bowel obstruction

${ }^{a}$ Readmissions account for all hospitalizations after discharge from initial treatment; ${ }^{\mathrm{b}}$ Information was obtained from medical records and by interview; ${ }^{\mathrm{c}}$ Includes some major morbidities or surgical procedures during initial hospitalization for treatment of $\mathrm{CDH}$ and all comorbidities after initial discharge

\section{Abbreviations}

BPD: Bronchopulmonary dysplasia; CDH: Congenital diaphragmatic hernia; HRQOL: Health-related quality of life; PedsQL: Pediatric Quality of Life Inventory; QoL: Quality of life; RRI: Recurrent respiratory infection

\section{Acknowledgments}

This project was supported by the Department of Anesthesiology and Perioperative Medicine at Mayo Clinic in Rochester, Minnesota. This research was conducted with departmental funds only.

\section{Funding}

This project was supported by internal funding from the Department of Anesthesiology and Perioperative Medicine at Mayo Clinic in Rochester, Minnesota. The funding source had no role in study design; in the collection, analysis and interpretation of data; in the writing of the report; and in the decision to submit the article for publication.

\section{Availability of data and materials}

The data used for this study is confidential and cannot be made public Individuals interested in obtaining specific data may contact Dr. Juraj Sprung (Sprung.juraj@mayo.edu).

\section{Authors' contributions}

KB: study design, data collection, manuscript preparation; RG: study design, data collection, manuscript preparation; JV: study design, data collection, manuscript preparation; LO: data collection, manuscript preparation; MG: study design, data collection; TC: data collection; TNW: data analysis, manuscript preparation; DRS: statistics, manuscript preparation; JS: study design, data collection, manuscript preparation; All authors read and approved the final version of manuscript.
Ethics approval and consent to participate

This study was approved by the Institutional Ethics Committee of the University Hospital Centre, Zagreb, Croatia. All procedures performed in studies involving human participants were in accordance with the ethical standards of the institutional and/or national research committee and with the 1964 Declaration of Helsinki and its later amendments or comparable ethical standards.

\section{Consent for publication}

Written, informed consent was obtained from all individual participants and/ or their legal guardians included in the study.

\section{Competing interests}

The authors declare that they have no competing interests.

\section{Publisher's Note}

Springer Nature remains neutral with regard to jurisdictional claims in published maps and institutional affiliations.

\section{Author details}

'Division of Neonatology, Department of Obstetrics and Gynecology, University Hospital Merkur, Zagreb, Croatia. ${ }^{2}$ Department of Pediatrics, School of Medicine, University of Zagreb, University Hospital Centre, Zagreb, Croatia. ${ }^{3}$ Division of Multispecialty Anesthesia, Mayo Clinic, 200 First Street SW, Rochester, MN 55905, USA. ${ }^{4}$ Division of Biomedical Statistics and Informatics, Mayo Clinic, Rochester, MN, USA. 
Received: 12 May 2017 Accepted: 25 February 2018

Published online: 14 March 2018

\section{References}

1. Grimaldi Capitello T, Fiorilli C, Placidi S, Vallone R, Drago F, Gentile S. What factors influence parents' perception of the quality of life of children and adolescents with neurocardiogenic syncope? Health Qual Life Outcomes. 2016;14:79.

2. Vetter TR, Bridgewater $C L$, McGwin G Jr. An observational study of patient versus parental perceptions of health-related quality of life in children and adolescents with a chronic pain condition: who should the clinician believe? Health Qual Life Outcomes. 2012;10:85.

3. Hyland ME. A brief guide to the selection of quality of life instrument. Health Qual Life Outcomes. 2003;1:24.

4. Gale CR, O'Callaghan FJ, Bredow M, Martyn CN. The influence of head growth in fetal life, infancy, and childhood on intelligence at the ages of 4 and 8 years. Pediatrics. 2006;118(4):1486-92.

5. Su CT, Wang JD, Lin CY. Child-rated versus parent-rated quality of life of community-based obese children across gender and grade. Health Qual Life Outcomes. 2013;11:206.

6. Bojanic K, Pritisanac E, Luetic T, Vukovic J, Sprung J, Weingarten TN, et al. Survival of outborns with congenital diaphragmatic hernia: the role of protective ventilation, early presentation and transport distance: a retrospective cohort study. BMC Pediatr. 2015;15:155.

7. Bojanic K, Pritisanac E, Luetic T, Vukovic J, Sprung J, Weingarten TN, et al. Malformations associated with congenital diaphragmatic hernia: impact on survival. J Pediatr Surg. 2015;50:1817-22.

8. Bojanic K, Grizelj R, Dilber D, Saric D, Vukovic J, Pianosi PT, et al. Cardiopulmonary exercise performance is reduced in congenital diaphragmatic hernia survivors. Pediatr Pulmonol. 2016;51:1320-9.

9. Bojanic K, Grubic M, Bogdanic A, Vukovic J, Weingarten TN, Huebner AR, et al. Neurocognitive outcomes in congenital diaphragmatic hernia survivors: a cross-sectional prospective study. J Pediatr Surg. 2016;51:1627-34.

10. Bouman NH, Koot HM, Tibboel D, Hazebroek FW. Children with congenital diaphragmatic hernia are at risk for lower levels of cognitive functioning and increased emotional and behavioral problems. Eur J Pediatr Surg. 2000;10:3-7.

11. Brownlee EM, Howatson AG, Davis CF, Sabharwal AJ. The hidden mortality of congenital diaphragmatic hernia: a 20-year review. J Pediatr Surg. 2009: 44:317-20.

12. Nobuhara KK, Lund DP, Mitchell J, Kharasch V, Wilson JM. Long-term outlook for survivors of congenital diaphragmatic hernia. Clin Perinatol. 1996;23:873-87.

13. Peetsold MG, Heij HA, Kneepkens CM, Nagelkerke AF, Huisman J, Gemke RJ. The long-term follow-up of patients with a congenital diaphragmatic hernia: a broad spectrum of morbidity. Pediatr Surg Int. 2009;25:1-17.

14. Peetsold MG, Huisman J, Hofman VE, Heij HA, Raat H, Gemke RJ. Psychological outcome and quality of life in children born with congenital diaphragmatic hernia. Arch Dis Child. 2009;94:834-40.

15. Peetsold MG, Vonk-Noordegraaf A, Heij HH, Gemke RJ. Pulmonary function and exercise testing in adult survivors of congenital diaphragmatic hernia. Pediatr Pulmonol. 2007:42:325-31.

16. Chen C, Jeruss S, Chapman JS, Terrin N, Tighiouart H, Glassman E, et al. Long-term functional impact of congenital diaphragmatic hernia repair on children. J Pediatr Surg. 2007;42:657-65.

17. Koivusalo A, Pakarinen M, Vanamo K, Lindahl H, Rintala RJ. Health-related quality of life in adults after repair of congenital diaphragmatic defects-a questionnaire study. J Pediatr Surg. 2005;40:1376-81.

18. Michel F, Baumstarck K, Gosselin A, Le Coz P, Merrot T, Hassid S, et al. Health-related quality of life and its determinants in children with a congenital diaphragmatic hernia. Orphanet J Rare Dis. 2013;8:89.

19. Poley MJ, Stolk EA, Tibboel D, Molenaar JC, Busschbach JJ. Short term and long term health related quality of life after congenital anorectal malformations and congenital diaphragmatic hernia. Arch Dis Child. 2004; 89:836-41.

20. Boloker J, Bateman DA, Wung JT, Stolar CJ. Congenital diaphragmatic hernia in 120 infants treated consecutively with permissive hypercapnea/ spontaneous respiration/elective repair. J Pediatr Surg. 2002;37:357-66.

21. Downard CD, Jaksic T, Garza JJ, Dzakovic A, Nemes L, Jennings RW, et al. Analysis of an improved survival rate for congenital diaphragmatic hernia. J Pediatr Surg. 2003;38:729-32.
22. Frenckner B, Ehren $\mathrm{H}$, Granholm T, Linden V, Palmer K. Improved results in patients who have congenital diaphragmatic hernia using preoperative stabilization, extracorporeal membrane oxygenation, and delayed surgery. J Pediatr Surg. 1997;32:1185-9.

23. Grizelj R, Bojanic K, Pritisanac E, Luetic T, Vukovic J, Weingarten TN, et al. Survival prediction of high-risk outborn neonates with congenital diaphragmatic hernia from capillary blood gases. BMC Pediatr. 2016;16:114.

24. Grizelj R, Bojanic K, Vukovic J, Novak M, Rodin U, Coric T, et al. Epidemiology and outcomes of congenital diaphragmatic hernia in Croatia: a populationbased study. Paediatr Perinat Epidemiol. 2016;30:336-45.

25. Varni JW. PedsQL [http://www.pedsql.org]. Accessed 11 Sept 2017.

26. Hill CD, Edwards MC, Thissen D, Langer MM, Wirth RJ, Burwinkle TM, et al. Practical issues in the application of item response theory: a demonstration using items from the pediatric quality of life inventory (PedsQL) 4.0 generic core scales. Med Care. 2007;45(5 Suppl 1):S39-47.

27. Varni JW, Limbers CA, Burwinkle TM. Impaired health-related quality of life in children and adolescents with chronic conditions: a comparative analysis of 10 disease clusters and 33 disease categories/severities utilizing the PedsQL 4.0 generic Core scales. Health Qual Life Outcomes. 2007;5:43.

28. Jobe AH, Bancalari E. Bronchopulmonary dysplasia. Am J Respir Crit Care Med. 2001;163:1723-9.

29. Congenital Diaphragmatic Hernia Study Group. Estimating disease severity of congenital diaphragmatic hernia in the first 5 minutes of life. J Pediatr Surg. 2001;36:141-5.

30. Schaad UB. OM-85 BV, an immunostimulant in pediatric recurrent respiratory tract infections: a systematic review. World J Pediatr. 2010;6:5-12.

31. Davis E, Nicolas C, Waters E, Cook K, Gibbs L, Gosch A, et al. Parent-proxy and child self-reported health-related quality of life: using qualitative methods to explain the discordance. Qual Life Res. 2007;16:863-71.

32. Ennett ST, DeVellis BM, Earp JA, Kredich D, Warren RW, Wilhelm CL. Disease experience and psychosocial adjustment in children with juvenile rheumatoid arthritis: children's versus mothers' reports. J Pediatr Psychol. 1991:16:557-68.

33. Theunissen NC, Vogels TG, Koopman HM, Verrips GH, Zwinderman KA, Verloove-Vanhorick SP, et al. The proxy problem: child report versus parent report in health-related quality of life research. Qual Life Res. 1998;7:387-97.

34. Varni JW, Limbers C, Burwinkle TM. Literature review: health-related quality of life measurement in pediatric oncology: hearing the voices of the children. J Pediatr Psychol. 2007;32:1151-63.

35. Glaser AW, Davies K, Walker D, Brazier D. Influence of proxy respondents and mode of administration on health status assessment following central nervous system tumours in childhood. Qual Life Res. 1997;6(1):43-53.

36. Lim Y, Velozo C, Bendixen RM. The level of agreement between child selfreports and parent proxy-reports of health-related quality of life in boys with Duchenne muscular dystrophy. Qual Life Res. 2014;23:1945-52.

37. Upton P, Lawford J, Eiser C. Parent-child agreement across child healthrelated quality of life instruments: a review of the literature. Qual Life Res. 2008;17:895-913.

38. Saigal S, Rosenbaum PL, Feeny D, Burrows E, Furlong W, Stoskopf BL, et al. Parental perspectives of the health status and health-related quality of life of teen-aged children who were extremely low birth weight and term controls. Pediatrics. 2000;105(3 Pt 1):569-74.

39. Schnadig ID, Fromme EK, Loprinzi CL, Sloan JA, Mori M, Li H, et al. Patientphysician disagreement regarding performance status is associated with worse survivorship in patients with advanced cancer. Cancer. 2008;113: 2205-14.

40. Slevin ML, Plant H, Lynch D, Drinkwater J, Gregory WM. Who should measure quality of life, the doctor or the patient? Br J Cancer. 1988;57:109-12.

41. Sheikh F, Akinkuotu A, Clark SJ, Zamora IJ, Cass DL, Olutoye O, et al. Assessment of quality of life outcomes using the pediatric quality of life inventory survey in prenatally diagnosed congenital diaphragmatic hernia patients. J Pediatr Surg. 2016;51:545-8. 